\title{
Study on Problem of Protection and Inheritance of Chinese Traditional Music
}

\author{
Zhicheng Li
}

Music College, Hubei Normal University, Hubei Huangshi, 435002, China

Keywords: Traditional music, Protection, Inheritance

\begin{abstract}
In recent years, protection and inheritance of traditional music have become cultural issues concerned by all sectors of society. Especially, in the market economy, we need to rescue the extremely weak traditional national folk music as far as possible. Thus it can be seen that how to protect and inherit Chinese traditional music has become an important problem faced by contemporary musicians. Based on elaborating the sources of Chinese traditional music, this paper analyzes the development situation of Chinese traditional music, and proposes specific protecting and inheriting strategies for Chinese traditional music.
\end{abstract}

\section{Introduction}

In the long history of traditional music of our country, people of all nationalities have created numerous outstanding traditional music works via their painstaking hands and suprising wisdom. For instance, the Dutar, Satar and other national music intruments used by Xinjiang Uygur people, instrument dance of Hunan Miao Nationality, Hip Collision Dance of Yunnan Pumi Nationality etc. not only show the regional difference and diversity of national music but also become the spiritual cohesion of people of all nationalities. People of ethnic minorities use music to show their rich emotions to serve their production and life and thus leave their own traces in the music history of our country. Nowadays, our society is in a brand-new era with rapid development of society and economy. In such a complicated and fickle society, the social lifestyles becomes increasingly diversified, modern people's mode of life and mode of thinking are changing ceaselessly; especially, their music taste has been totally different from that in the past, and has become more modernized. Therefore, the Chinese traditional music needs to face new challenges and it is especially important to enhance the protection and inheritance of Chinese traditional music.

\section{Elaboration of resources of Chinese traditional music}

If classified from separate categories, Chinese traditional music can be mainly classified into folk song, folk instrument music, song-dance music, opera muci and other forms. A large number of precious music resources were contained in the chanties in primitive society, chime dance music in the pre-Qin period, court-ball dances in Tang and Song dynasties and Chinese opera arts after the Yuan and Ming dynasties. Chinese traditional music developed in a new way after the Opium War. In the development of feudal society, the classical court music symbolizing the feudal rulers lost its practical meaning because it is largely divorced from people's real life. At that time, traditional folk music kept a very close relationship with people so the folk music developed rapidly. After the establishment of new China, music works embodying people's new life came to the fore one after another, and such music works have full-bodied national characteristics. After the reform and opening-up policy in the 1980s, with the continuous development of science, technology, society and economy, people can appreciate the latest music works through the broadcast, TV, video, internet and other modern media, causing that people's auditory nerve to be stimulated ferociously and people obtained strong the feeling of freshness. For this reason, the traditional music failed to compete with modern music. In this way, in the process of competing with extraneous music, the traditional music lost numerous audiences. Thus it can be seen that the development of Chinese traditional music is not optimistic. 


\section{Analysis on development situation of Chinese traditional music}

At present, much minority music works has already been excavated and used in musical practices. Originally little-known traditional music started to became unveiled and gradually be known, accepted and recognized by the outside world. Seeking difference and innovation can be called the nature of human being. In moden metropolises, people feel mentally and physically exhausted with the nosiy environment and rapid pace of life, so returning to nature is accepted by an increasing number of people. This mentality reflected in music is the upsurge of traditional music. The reputation of The Girl from Dabancheng and other classical ethnic songs is greatly boosted. This proved a fact that the pure and simple style in traditional music extremely complies with the modern city dwellers' taste, because it can provide them with amazing imaginations. The traditional national works and minority musicians' performances, which have already been widely accepted and recognized by urban audiences, play significant roles in the current musical market. As proven in historical experience and current situation, collisions among heterogeneous cultures usually input brand-new elements to the opposite side in the hope of enhance their abilities. Once the traditional music rapidly follows the pace of social development, breaks through its development space, and actively imitate and absorb the diversified forms of contemporary music, it can naturally show its huge vitality again.

The social function of music and the relationship with social activities are largely different in different development phases. The musical characteristics in modern market economy are mainly that music can be recorded by sound and transmitted independently with electronic media. Due the long-term lag of economy, Chinese minorities' musical forms get more close to the natural status. Music is extremely closely related to social activities, highly relies on social life, and has all kinds of social functions such as religion, entertainment and cultural inheritance. In the past, a music composer was a music performer. Nowadays, the improvement in economic development level has caused changes in people's lifestyle. When people realize the increasing opening due to the influences from outside world, the diversified lifestyles and thinking methods usually will reduce the group consciousness, and the vitality of collectively participating in musical creation will disappear due to the sharp reduction in the traditional social activities, which it depends on for existence. All of these are the profound crises faced by Chinese traditional music.

\section{Specific strategies for protection and inheritance of Chinese traditional music}

Preservation and development has always been the key contents in the protection of Chinese traditional music. After going through economic development, many developing countries' traditional music usually undergo the process from being overlooked to returning. We should say that this is an inevitable phase of current social development. We must comprehensively learn from past experience and lessons, make full mental preparations for protection and inheritance of traditional music, and thus can minimize the winding courses. Of course, protection is not equal to preservation without making any progress. Some may think that authentic preservation means traditional music naturally staying at the previous development period. However, this is actually antipathetic with the law of historical development, so this does not comply with the minorities' fundamental interests. In the course of historical development, a cultural variation cannot be stopped by people, so only continuous innovation can achieve inheritance and further development of traditional music. Meanwhile, we should not neglect another crucial issue that there isa a drastic change rather than step-by-step evolution in the development of minority regions with the fierce shock of modernization. Such a change directly leaps from the elementary phase to the senior phase, so there is likely to cause a break in the inheritance of culture. Once it is difficult to record and preserve the inherent cultural patterns, a large number of precious music heritages may disappear; such a loss cannot be redeemed once it occurs. Now, the traditional music should not only undergo a historical leap but also bear the hudge shock of cultures of other nations. Once proper changes fail to be completed timely, the traditional music can not be inherited, causing the disappearance of traditional music culture. In view of this, protection actually contains preservation and development. Large-scale collection, 
systemization, preservation and other work should be conducted before the ancient music without survival encironment disappears so as to ensure that Chinese traditional music gene pool can be relatively complete, find a sustainable road for traditional music in contemporary society, avoid breakages in inheritance, and thus reserve a space for traditional music in Chinese music territory. Preservation is to keep the original shape on the premise that the object is in its original shape. The author thinks that establishing traditional music culture museums is one of the good ways to protect and inherit the traditional music. All preserved objects can be practically and effectively maintained by using comprehensive collection, collective custody, standardized administration and other means. According to the difference of collected musical objects, such museums mainly have the following three patterns,

Firstly, build exhibition halls for traditional music object. Painstakingly collect all kinds of traditional musical instruments, life-related costumes, props and other material objects, pictures etc. as objects preserved. An exhibit should not only have a great study value but also have a value of cultural relic collection. On this basis, provide people with more chances to contact and understand the specific condition of minority music by convening the material object exhibition of traditional music to further improve their interest in Chinese traditional music. In this way, it can largely help to promote the further propagation and development of Chinese traditional culture. Secondly, establish traditional music archives. Historical documents of music in minority areas, traditional music scores and videotapes collected, systemized and recorded by traditional music researchers, and discussions about traditional music written by them should be considered as the major objects preserved. In Chinese history, rules of all times usually tended to focus on court music and Han music but neglect folk music and minority music, so Chinese traditional music hasn't been emphasized all the time; in addition, due to the limitation of most minorities' cultural development level, such minorities didn't have the ability of independently explore and record their music, so historical documents and data about traditional music handed down up to now are very few. Fortunately, the traditional music includes another type of extremely abundant intangible inheritages handed down, which are all sorts of live music spreading in civil society. Such type of music was generated in their areas and groups through oral transmission and oral imparting, and was passed on and preserved from generation to generation. Up to this day, such music has become the precious living fossile in studies on Chinese traditional music. Nowadays, the survival environments for plenty of ancient musical types are deteriorating year by year and ancient musical types face the danger of losing their old prototypes and even disappearance. Therefore, the researchers on Chinese traditional music must feel obliged to bear the significant responsibility given by the history, use more forms and means to practically convert traditional music heritages, which are likely to disappear easily, into long-lasting documents, record them in written through musical scores accompanied by corresponding audio and video records, objectively describe musical elements of different nationalities in the character form, and compile the record for Chinese traditional music on this basis. In this way, a long-lasting archive can be established for Chinese traditional music. Thirdly, build ecological exhibition halls for traditional music. It means to artificially preserve the original situation of our traditional national music in a relatively small scope, so some types of precious traditional music can be preserved here in a fresh and alive way. For instance, most of our minorities can sing and dance well, so they have extremely numerous high-quality music works with a rather high ornamental value. Once the above music types can only be preserved in the static museum, we can say that it is a complete waste of Chinese traditional music resources. Abundant developable tourism resources lurk in numerous minority areas. Especially, the unique natural sceneries and fetching national customs have already attracted an increasing number of tourists. In recent years, folk culture villages or national ecological protection parks and other carriers have been built in the scenic spots in many national areas, so the original situation of traditional music culture can be preserved in an independent space and is not likely to be affected by the outside world. In this place, tourists can personally experience people's traditional lifestyles and customs in national areas, and thus contact the ancient minority music forms with their styles different from Han music. In this sense, the author thinks that we can call this type of place exhibiting national traditional music as the 
dynamic music museum. This measure closely connecting the natural landscape with human landscape will bring a very large development space for tourism in the national area, create abundant economic benefits and obtain high social benefits. It is worth mentioning that the relationship between both sides needs to be well controlled and having partiality for any side is not allowed.

\section{Conclusion}

To sum up, the Chinese traditional music, which is a quintessence part in the treasure house of Chinese national culture, has followed the ancient principles up to now, and still has a particularly significant value in modern society. For instance, how to protect and inherit the music works orally transmitted and imparted from generation to generation at the transition of times shift? Some music workers transcribe national music by recording, a form of producing modern music; this is warmly welcomed by minority compatriots and the common people so that the traditional music art can healthily spread and develolp in civil society. Next, Chinese music workers should commit themselves to exploring the development space for traditional music, actively simulating and absorbing contemporary music elements, and show the sense of the times in traditional music so as to practically satisfy contemporary people's brand-new spiritual pursuits. Therefore, Chinese traditional music can have more extensive mass base and thus be grealy vigorous again.

\section{References}

[1] Zeng Suijin. Introduction to Sociology of Music - Stuy on Operation of Music Production System in Contemporary Society. Beijing: Culture and Art Publishing House, 1997.

[2] Qi Yidan and Jian Xin. Introduction to National Music. Beijing: Jinghua Press, 2001.

[3] Wang Yuhe. Chinese Modern Musical History (revised edition). Beijing: People's Music Publishing House, 2002.

[4] Li Fei. Development and Music Spreading of Chinese Traditional Music. Journal of Hubei Normal University (Philosophy and Social Science), 2008 (3).

[5] Zhou Xuguang and Li Haixia. Discussion on the Problem of Inheriters in Protection of Chinese Traditional Music. Career Horizen, 2010 (2010) 